\title{
Study of Pre-Hospital Cardio Pulmonary Resuscitation (CPR) Outcomes and Relevant Factors in Ardabil City between 2012 and 2013
}

\author{
Mehri Seyed Javadi ${ }^{1}$, Raheleh Mohammadi ${ }^{1}$, Maryam Seyed Javadi ${ }^{2}$, Mehdi Ja'fari Oory ${ }^{3} \&$ Mohammad $^{\prime}$ \\ Yazdani Yengejeh ${ }^{4}$ \\ ${ }^{1}$ Instructor and Faculty Member of Nursing University Ardabil Medical Science, Iran \\ ${ }^{2}$ Health Services Management at Iran University of Medical Science, Iran \\ ${ }^{3}$ University of Welfare and Rehabilitation Sciences, Tehran, Iran \\ ${ }^{4}$ Emergency Medical Services Ardebil, Ardebil University of Medical Sciences, Iran \\ Correspondence: Mehdi Ja'fari Oory, Ph.D. Nursing Student in University of Welfare and Rehabilitation \\ Sciences, Tehran, Iran. Tel: 91-4197-3745. E-mail: me.jafari@uswr.ac.ir
}

Received: March 18, 2016 Accepted: April 25, 2016 Online Published: May 6, 2016

doi:10.5539/gjhs.v8n12p258 URL: http://dx.doi.org/10.5539/gjhs.v8n12p258

\begin{abstract}
Background \& Objectives: Cardio Pulmonary Resuscitation (CPR) is a procedure which was done both in hospital or pre-hospital in order to return life after clinical death. Although the most cardiac attacks happen out of hospital, but there are lack of existing studies related to CPR assessment in pre-hospital conditions. Then this study carried out in order to show the outcome of pre-hospital CPR procedures and its related factors in Medical Emergency Centers of Ardebil city.
\end{abstract}

Method: This descriptive cross-sectional study was conducted on 272 CPR cases in the Emergency Medical Center (EMS) in Ardabil, between 2012 and 2013. The researcher-made questionnaire was used. For data analyzing the descriptive and analytical statistical method such as the Chi-square test and the Chi-square details test were used with SPSS 16 software. The values of $\mathrm{P}<0.05$ were considered significant.

Results: The overall rate of successful CPR reported only 19.1\%. The mean (SD) of patient's age was $74.19 \pm 79.60$ years and the most of them $(66.2 \%)$ were men. The most patients $(64.3 \%)$, had heart problems as a chief complaint. From all CPRs, $83.1 \%$ and $11.5 \%$ were done in patient homes and public place respectively. There was no statistically significant relationship between the successful CPR with age $(p=0.15)$, sex $(p=0.44)$, the arrival time of emergency personnel to the scene $(\mathrm{p}=0.98)$ and patient's pulse rate $(\mathrm{p}=0.52)$. But there was statistically significant relationship between the successful CPR with underlying diseases $(\mathrm{p}=0.003)$, Location of $\mathrm{CPR}(\mathrm{P}=0.002)$, patient blood pressure $(\mathrm{p}=0.00)$ and patient respiratory rate $(\mathrm{p}=0.04)$.

Conclusion: According to the findings, the rate of successful CPR was at a low level in the pre-hospital that need to be investigated further about its cause and its related factors.

Keywords: cardio pulmonary resuscitation (CPR), pre-hospital emergency care, emergency medical service (EMS)

\section{Introduction}

Over the years and by science developments, significant progresses have been occurred in Cardiopulmonary Resuscitation (Jafarian, 2002), but the rate of final survivals is not still ideal, and the statistics of survivals among countries confirm it. The rate of ultimate success of CPR in out of hospital cardiac arrest reported $1.4 \%$ to $29 \%$ and this rate in larger cities is some lower and in the small cities is some higher (Mutchner, 2007). Annually patients who are undergoing to CPR are about 400,000 in the United States, but unfortunately most of them are unsuccessful (Timerman et al., 2004). According to various studies in Iran, the rate of successful CPR have been reported from 7\% to 29\% (Jafarian, 2002; Saifi et al., 2010a; Salari, 2010). According to the results of studies in other countries, the initial and final success (discharge time) of resuscitation was reported $61 / 2 \%$ and $32 / 2 \%$ respectively (Travers et al., 2010). Although the most cardiac attacks happen in out of hospitals or houses, but it is less possibile that performing of CPR could be standard for victims (Keim et al., 2001; Jackson \& Swor, 1997). 
It should be noted that providing CPR with very good quality is directly related to improving the outcomes of operations in out of hospital cardiac arrest (Bobrow et al., 2008; Roosa et al., 2013). The standard CPR are critical for surviving of all victims whit early cardiopulmonary arrest (Keim et al., 2001). Since $1950^{\text {th }}$, the CPR started with external heart massage for cardiac arrest due to acute coronary syndromes and anesthesia complications for the first time, but gradually it was used for more cases such as, drowning, electric shock, poisoning, acute myocardial infarction whit sudden cardiac arrest and many other cases(Sandroni et al., 2007; Chang et al., 2009). The CPR is the procedures to resuscitate vital functions of heart and lungs and it is an effort for artificial blood circulation and respiration until return of the automatic normal conditions (Salari \& Mohammadnejad, 2010). Although, the CPR process have had many progresses, but the death rate due to sudden cardiac arrest is still higher than other death cases (N, 2009). Survival after the CPR depends on immediate performance of emergency team, timely use of defibrillation and respiratory support procedures (Youn et al., 2009). In order to reduce the mortality due to sudden cardiac arrest, researchers have paid much attention to the quality of CPR, factors leading to successful CPR, and increasing the efficiency of out of hospital CPR(Franek, Pokorna, \& Sukupova, 2010). The likelihood of successful CPR in the out-of-hospital depends on many factors. According to studies, the rate of success depends on the first recorded rhythm of patient, the duration of resuscitation, the interval between collapse and starting resuscitation and the interval between collapse and the first electric shock (Franek et al., 2010; Goodarzi et al., 2015). Furthermore, the studies showed that the success rate of CPR can vary according to underlying reasons, for instance patient age, underlying diseases, the interval time between cardiopulmonary arrest and starting the resuscitation (Goodarzi et al., 2015) and the preparation of resuscitation team are the factors associated with a successful resuscitation (Jafarian, 2002). Because of the CPR process had critical role to resuscitate patient life and the several factors could be associated with the successful $\mathrm{CPR}$, and also with regarding to the absence of coherent studies in pre-hospital condition in Iran, this study was conducted with the aime of assessing outcomes of CPR in pre-hospital in Ardebil city between 2012 and 2013.

\section{Method}

This cross-sectional study was conducted between March 2012 and December 2013. The research environment included all Emergency Medical Centers in Ardabil city. The inclusion criteria were all the CPR cases among all emergency medical dispatching services in this period of time and exclusion criteria was limited to those whose information were not recorded any or not recorded completely.

After obtaining satisfaction from the authorities in Ardabil University of Medical Sciences and Medical Emergency Center, the researcher founded 272 CPR cases with census method as a study population among all emergency medical dispatching services (22759) from March 2012 to December 2013.

The data collection tool was a researcher-made questionnaire based on review of literature and dispatching card of medical emergency services of Ardebil province. In order to determine the validity of the questionnaire, Content validity was applied. Thus the questionnaire was given to 5 members of the Faculty of Medical Sciences and 5 members of the emergency team, and then their corrective comments applied. The reliability of the questionnaire was determined through Cronbach's alpha coefficient (89.28\%). The reliability was also confirmed using with a pilot study and completing data gathering based on the records of 30 patients undergoing CPR by two expert advisors in the study and according to the Kappa concordance coefficient achieved 0.85 . The questionnaire had two parts: The first part included demographic information (age, sex, chief complain and past medical history), and the second part included items about arrival time to the scene, place and outcome of the CPR, the patient's vital signs, drugs, underlying diseases, the difference between time of reaching to the scene and receiving interventions. The researcher and medical emergency team completed questionnaire according to patient records in emergency medical centers. For data analyzing the descriptive statistical method for categorization of CPR outcomes and analytical statistical method such as the Chi-square test, the Chi-square details test were used for assessment of the significant relationship between CPR outcomes and demographic variables with SPSS 16 software. The values of $\mathrm{P}<0.05$ were considered significant

\section{Results}

The average age of the cases was $60.79 \pm 19.74$. The rate of successful CPR was only $19.1 \%$ among all of CPR cases (Figure 1). 


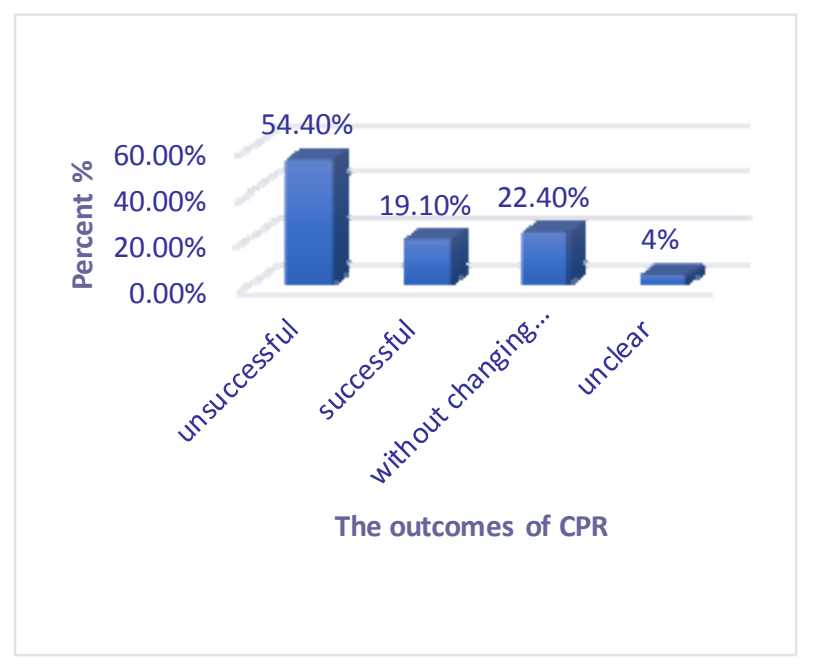

Figure 1. Frequency of the CPR outcomes

According to Table 1, the most of the patients were male and had a cardiac problem and a history of cardiac diseases. The most CPR was done in patient houses. The arriving time to the scene by ambulance personnel was usually between 4 and 8 minutes.

Table 1. The probability and significant level in relationship of CPR outcome with the demographic characteristics

\begin{tabular}{|c|c|c|c|c|}
\hline \multicolumn{2}{|c|}{ Demographic Characteristics } & \multirow{4}{*}{$\begin{array}{l}\text { Frequency } \\
180\end{array}$} & \multirow{4}{*}{$\begin{array}{l}\begin{array}{l}\text { Percentage } \\
(\%)\end{array} \\
66.2\end{array}$} & \multirow{5}{*}{$\begin{array}{l}\text { The probability and significant level } \\
\text { in relationship of CPR outcome with } \\
\text { the underlying variable } \\
\text { Pearson Chi-Square }=5.31 \\
\mathrm{P}=0.15 \\
\text { Cramer's } \mathrm{V}=0.14 \\
\mathrm{P}=0.15\end{array}$} \\
\hline \multirow{4}{*}{ sex } & & & & \\
\hline & Male & & & \\
\hline & & & & \\
\hline & Female & 92 & 33.8 & \\
\hline \multirow{5}{*}{ Age (year) } & $<20$ & 10 & 3.7 & \multirow{6}{*}{$\begin{array}{l}\text { Pearson Chi-Square }=11.97 \\
\mathrm{P}=0.44 \\
\text { Cramer's V=0.12 } \\
\mathrm{P}=0.44\end{array}$} \\
\hline & $20-40$ & 34 & 12.5 & \\
\hline & $40-60$ & 80 & 29.4 & \\
\hline & $60-80$ & 111 & 40.8 & \\
\hline & $>80$ & 37 & 13.6 & \\
\hline \multirow{8}{*}{$\begin{array}{l}\text { Main } \\
\text { Complains }\end{array}$} & Cardiac Problems & 175 & 64.3 & \\
\hline & $\begin{array}{l}\text { Disturbance of } \\
\text { consciousness }\end{array}$ & 39 & 14.3 & \multirow{7}{*}{$\begin{array}{l}\text { Pearson Chi-Square }=42.83 \\
\mathrm{P}=0.03 \\
\text { Cramer's } \mathrm{V}=0.22 \\
\mathrm{P}=0.03\end{array}$} \\
\hline & Accident & 9 & 3.3 & \\
\hline & $\begin{array}{l}\text { Poisoning with } \\
\text { Monoxide Carbon }\end{array}$ & 16 & 5.9 & \\
\hline & Paroxysm & 3 & 1.1 & \\
\hline & Hanging \& Suicide & 3 & 1.1 & \\
\hline & $\begin{array}{l}\text { Respiratory } \\
\text { Problems }\end{array}$ & 11 & 4.0 & \\
\hline & Other Factors & 16 & 5.9 & \\
\hline \multirow{3}{*}{$\begin{array}{l}\text { Arriving Time } \\
\text { to the Scene }\end{array}$} & $\begin{array}{l}\text { Less than } 4 \\
\text { Minutes }\end{array}$ & 31 & 11.4 & \multirow{3}{*}{$\begin{array}{l}\text { Pearson Chi-Square }=2.17 \\
\mathrm{P}=0.98 \\
\text { Cramer's V=0.52 }\end{array}$} \\
\hline & 4 Minutes & 34 & 12.5 & \\
\hline & 4-8 Minutes & 155 & 57.0 & \\
\hline
\end{tabular}




\begin{tabular}{lllll}
\hline & More than 8 & 52 & 19.1 & $\mathrm{P}=0.98$ \\
& Minutes & & 83.1 & Pearson Chi-Square=18.76 \\
& Private residence & 226 & 0.7 & $\mathrm{P}=0.40$ \\
& Educational Place & 2 & 11.5 & Cramer's V=0.15 \\
& Public Places & 30 & 5.1 & $\mathrm{P}=0.40$ \\
& Other & 14 & 18.8 & \\
& NO Underlying & 51 & 44.9 & \\
Underlying & Diseases & & 7.7 & Pearson Chi-Square $=20.24$ \\
& Cardiac Problems & 122 & 4.8 & $\mathrm{P}=0.50$ \\
& Blood Pressure & 21 & 3.3 & Cramer's V=0.15 \\
& Stroke & 13 & $\mathrm{P}=0.50$ \\
& Substance Abuse & 9 & 7.4 & \\
& Diabetes & 20 & 4.0 & \\
& Surgery History & 11 & 9.2 & \\
& Others & 25 & & \\
\hline
\end{tabular}

According to Table 1, there was no statistically significant relationship between the outcome of CPR with arriving time of ambulance personnel to the scene $(\mathrm{p}=0.98)$, age of the patients $(\mathrm{p}=0.44)$, gender $(\mathrm{p}=0.15)$, the Underlying Diseases $(\mathrm{p}=0.50)$ and CPR Place $(\mathrm{P}=0.40)$. But the relation between the outcome of CPR and the chief complain was statistically significant $(\mathrm{p}=0.03)$. Also the patient vital signs (Blood Pressure, Respiratory Rate and Pulse Rate) before of the CPR and relationship of them with the outcome of the CPR and their significant level were reported in Table 2.

Table 2. Shows the patient vital signs before beginning of the CPR and their relationship with outcome of the CPR

\begin{tabular}{|c|c|c|c|c|}
\hline Vital Sign & $\begin{array}{l}\text { Amount } \\
\text { variable }\end{array}$ & Frequency & percentage & $\begin{array}{l}\text { The probability and significant level in } \\
\text { relationship of outcome of the CPR with vital } \\
\text { sign }\end{array}$ \\
\hline \multirow{4}{*}{$\begin{array}{l}\text { Systolic Blood } \\
\text { Pressure }\end{array}$} & $0-50$ & 78 & 26.4 & \multirow{4}{*}{$\begin{array}{l}\text { Pearson Chi-Square }=41.32 \\
\mathrm{P}=0.00 \\
\text { Cramer's V }=0.57 \\
\mathrm{P}=0.00\end{array}$} \\
\hline & $50-100$ & 46 & 16.9 & \\
\hline & $100-150$ & 1 & 0.4 & \\
\hline & $\begin{array}{l}\text { Not clear and } \\
\text { without recording }\end{array}$ & 146 & 53.7 & \\
\hline \multirow{4}{*}{$\begin{array}{l}\text { Respiratory } \\
\text { Rate }\end{array}$} & $0-12$ & 21 & 7.7 & \multirow{4}{*}{$\begin{array}{l}\text { Pearson Chi-Square }=12.05 \\
\mathrm{P}=0.04 \\
\text { Cramer's V }=0.33 \\
\mathrm{P}=0.04\end{array}$} \\
\hline & $12-20$ & 7 & 2.6 & \\
\hline & $20<$ & 26 & 9.6 & \\
\hline & $\begin{array}{l}\text { Not clear and } \\
\text { without recording }\end{array}$ & 218 & 80.1 & \\
\hline \multirow{4}{*}{ Pulse Rate } & $0-60$ & 15 & 5.5 & \multirow{4}{*}{$\begin{array}{l}\text { Pearson Chi-Square }=3.17 \\
\mathrm{P}=0.52 \\
\text { Cramer's V }=0.19 \\
\mathrm{P}=0.52\end{array}$} \\
\hline & $60-100$ & 18 & 6.6 & \\
\hline & $100<$ & 9 & 3.3 & \\
\hline & $\begin{array}{l}\text { Not clear and } \\
\text { without recording }\end{array}$ & 230 & 84.6 & \\
\hline
\end{tabular}

According to Table 2, there was statistically significant relationship between the outcome of CPR with the patient Blood Pressure $(p=0.00)$ and Respiratory Rate $(p=0.04)$. But the relation between outcome of CPR and the patient pulse rate Respiratory Rate was not statistically significant $(\mathrm{p}=0.52)$. 


\section{Discussion}

The study showed that, among all 272 patients were undergoing CPR over 2 years, only 19/1\% of them had successful outcomes and finally were taken to the hospital with good vital signs, normal heart and breathing function. The successful CPR rate in other studies are as follow: $28.1 \%$ in Kermanshah (Saifi et al., 2010b), $29.3 \%$ in Shohadaye Haftom Tir, Tehran (Jafarian, 2002), 28.4\% in selected educational centers of Tehran (Salari \& Mohammadnejad, 2010), 19.9\% in educational centers of Kashan (Ebell et al., 1998), 32\% in Social Security emergency hospitals of Alborz Province (Nasiripour, Masoudi, \& Fathi, 2012), 39.7\% in Brazil (Moretti et al., 2007), $10.6 \%$ in Kermanshah (Goodarzi et al., 2015). One study showed that in critical ward, the rate of successful CPR was 3.3\% (Jaberi, Changizian, \& Mazlomzadeh, 2011; Karetzky, Zubair, \& Parikh, 1995) and in other ward, this rate vary from 13\% to 33\% (Abella et al., 2005; Brindley et al., 2002; Taffet, Teasdale, \& Luchi, 1988), also the successful CPR reported from $8 \%$ to $16 \%$ in some other studies (Karetzky et al., 1995). In Goodarzis study which was conducted in hospital, The ultimate success rate of resuscitation was $10.6 \%$, and at six-month follow-up survey data on patients after discharge, the long-term success rate of the resuscitation was as $8.87 \%$ (Goodarzi et al., 2015). As the successful CPR depends on several factors and because of this study carried out in the pre-hospital environment, thus the rate of success can be different in comparison with previous studies that assessed the CPR outcomes in hospital with enough personnel and equipment. In this regard, Philip (2012) states that despite the progress in medical procedures and medical devices, the results and prognosis in patients with sudden cardiopulmonary arrest is still weak (Goodarzi et al., 2015).

In this study, the average patient age was over of 61 years and most of them were male. In this respect a study showed that the patient average ages were 67 years and old but more than half of them were female (Jaberi et al., 2011). In Vakmer's study this average number was 67 (Vukmir, 2006). Further studies in pre-hospital environment or in hospital also showed that the patients average age were more than 60 years old and more than half of them were male (Monsieurs et al., 2012; Nasiripour et al., 2012; Taffet et al., 1988). Regarding to result of this study and comparing with other similar studies, we could conclude that the majority of patients who undergoing CPR are male with older age. This study showed no statistically significant relationship between age and sex with CPR success rate. These results are consistent with the study which conducted in 2012 in the hospitals of Alborz province (Nasiripour et al., 2012), the conducted study at Imam Khomeini Hospital, Babol in 2010 (Brimnejad, 2009), Jaberi's study in 2011 and Goodarzi's study in 2013 (Goodarzi et al., 2015). But in Jaberi's study there was no statistically significant relationship between sex and CPR result, but there was statistically significant relationship between age and the successful CPR, Which means that the ultimate result of CPR in younger patients is significantly more successful (Jaberi et al., 2011). Also in one study, the rate of successful CPR was higher in male patients (Jafarian, 2002). Some other studies showed that the surviving rate after CPR in older patients is at the lower level in comparison with younger patients (S. Cooper, Janghorbani, \& G. Cooper, 2006; Chang et al., 2009). As mentioned above there are conflict result in relationship of age and sex with CPR and need to more studies. In this study the age of only a few patients (7 patients) were lower than 40 years then the statistical results can't show significant relationship between the age and successful CPR. This study also was carried out in pre-hospital environment rather than in the hospital and thismight leaded to different results. In this respect, certainly it can not be said that the age can be the main factor in the success or failure results of the CPR, because other factors such as underlying diseases- especially in the old patients also could impact on the results of the CPR (Khalafi, Ravakhah, \& West, 2001; Chang et al., 2009).

Based on the present study results, statistically there was no significant relationship between underlying diseases and CPR outcome. The greatest initial success rate of CPR was related to the underlying cardiac diseases. which are consistent with the results of researches conducted in hospitals of kermanshah in 2013 (Goodarzi et al., 2015), Hospitals of Kashan in 2003 and some overseas other studies (Jeresaty, Liss, \& Basu, 1973; MH et al., 1998; WILDSMITH, 1972) In this regard, Jafariyan reported that the greatest success rate was related to medicine poisoning, and he also mentioned that the success rate was in the lower level in trauma cases in comparison with patients with underlying internal, cardinal, kidney, lungs and neural diseases and also CPR was not successful in any patients with cancer (Jafarian, 2002). According to Goodarzi study, the greatest initial successful CPR rate was related to the poisoning cases, the heart diseases and malignancies respectively (Goodarzi et al., 2015). According to Jaberi's study the greatest number of successful CPR was due to underlying neurology problems (Jaberi et al., 2011). In this regard, it can be said that patients with cardiac problem may call to EMS centers immediately because of cardiac pain severity and then because of their fast response and intervention, it doesn't happen unpleasant side effects for the patient.

In this study, there was significant relationship of CPR outcome with patient blood pressure and respiratory rate. There was not significant relationship between CPR outcome and arrival time to the scene similar of these 
founding wasn't found by the researcher from the literature. In this study, the most CPRs were done firstly at private residence and then at public place that were consistent with previous studies (Olasveengen et al., 2009; Jacobs et al., 2011).

\section{Conclusion}

This study showed that the rate of successful CPR is very low. In this respect an integrated research has not carried out yet and almost this is the first study in Iran and also there are no totally similar studies in the other countries, thus more studies are required due to assessment of relevant factors such as the skill of the medical emergency team, available equipment and ... According to this study, the most patients undergoing to CPR had the cardiac based disease and also the most successful CPR was related to them. Then, it is May that the underlying diseases could predict the CPR outcome.

\section{Limitations}

In this study the most barriers to take best result was the lack of data according to absence of complete patient characteristics record information in EMS centers. Then the researchers couldn't report some valuable data such as primary patient arrhythmia, the elapsed time after cardiac collapse, all patient-vital signs and drugs used at CPR. Also, because of the lack studies related to pre-hospital CPR in Iran, researcher compared the finding of this study with the outcome of CPR in hospitals instead that pre-hospital like Goodarzi study.

\section{Recommendation}

There is need to more extensive researches should be done on other MES centers in other cities with focusing of mentioned deficiencies of present study in order to reach to the further improvements of out of hospital CPR.

\section{Funding/Support}

This paper has been derived from the results of an approved research project No. 6630 by university of Ardabil medical science.

\section{Competing Interests Statement}

The authors declare that there is no conflict of interests regarding the publication of this paper.

\section{References}

Abella, B. S., Alvarado, J. P., Myklebust, H., Edelson, D. P., Barry, A., O’Hearn, N., ... Becker, L. B. (2005). Quality of Cardiopulmonary Resuscitation during in-Hospital Cardiac Arrest. JAMA: The Journal of the American Medical Association, 293(3), 305-10. http://dx.doi.org/10.1001/jama.293.3.305

Anon. (n.d.) Olasveengen, Theresa M., Inger Lund-Kordahl, Petter A. Steen, and Kjetil Sunde. Out-of Hospital Advanced Life Support with or without a Physician: Effects on Quality of CPR and outcome. Resuscitation, $80(11), 1248-1252$.

Bobrow, B. J., Clark, L. L., Ewy, G. A., Chikani, V., Sanders, A. B., Berg, R. A., ... Kern, K.B. (2008). Minimally Interrupted Cardiac Resuscitation by Emergency Medical Services for out-of-Hospital Cardiac Arrest. JAMA: The Journal of the American Medical Association, 299(10), 1158-65. http://dx.doi.org/10.1001/jama.299.10.1158

Brimnejad, L. (2009). Presence Effect of Professional Resuscitate on Cardiopulmonary Resuscitation Outcome in Emam Khomeyni Hospital. J Babol Univ Med Sci, 10(3), 55-61. Retrieved December 27, 2015 from https://scholar.google.com/scholar?q=Presence + effect + of + professional + resuscitat + on + cardiopulmonary + re suscitation+outcome+in+Emam+Khomeyni+hospital\&btnG=\&hl=en\&as_sdt=0\%2C5\#0

Brindley, P. G., Markland, D. M., Mayers, I., \& Kutsogiannis, D. J. (2002). Predictors of Survival Following in-Hospital Adult Cardiopulmonary Resuscitation. CMAJ: Canadian Medical Association Journal=Journal de l'Association Medicale Canadienne, 167(4), 343-48. Retrieved from http://www.pubmedcentral. nih.gov/articlerender.fcgi?artid $=117846 \&$ tool=pmcentrez\&rendertype $=$ abstract

Chang, W.-H., Huang, C.-H., Chien, D.-K., Su, Y.-J., Lin, P.-C., \& Tsai, C.-H. (2009). Factors Analysis of Cardiopulmonary Resuscitation Outcomes in the Elderly in Taiwan. International Journal of Gerontology, 3(1), 16-25. http://dx.doi.org/10.1016/S1873-9598(09)70016-X

Cooper, S., Janghorbani, M., \& Cooper, G. (2006). A Decade of in-Hospital Resuscitation: Outcomes and Prediction of Survival? Resuscitation, 68(2), 231-37. http://dx.doi.org/10.1016/j.resuscitation.2005.06.012

Ebell, M. H., Becker, L. A., Barry, H. C., \& Hagen, M. (1998). Survival after in-Hospital Cardiopulmonary Resuscitation. Journal of General Internal Medicine, 13(12), 805-16. http://dx.doi.org/10.1046/j. 
1525-1497.1998.00244.x

Franek, O., Pokorna, M., \& Sukupova, P. (2010). Pre-Hospital Cardiac Arrest in Prague, Czech Republic-The Utstein-Style Report. Resuscitation, 81(7), 831-35. http://dx.doi.org/10.1016/j.resuscitation.2010.03.005

Goodarzi, A., Jalali, A., Almasi, A., Naderipour, A., Kalhorii, R. P., \& Khodadadi, A. (2015). Study of Survival Rate after Cardiopulmonary Resuscitation (CPR) in Hospitals of Kermanshah in 2013. Global Journal of Health Science, 7(1), 52-58. Retrieved December 26, 2015, from http://dx.doi.org/10.5539/gjhs.v7n1p52

Jaberi, Y., Changizian, L., \& Mazlomzadeh, S. (2011). Predictors of Outcome in In-Hospital Cardio-Pulmonary Resuscitation. ZUMS Journal, 19(75), 48-57. Retrieved December 27, 2015, from http://www.zums.ac.ir/journal/browse.php?a_code=A-10-4-579\&slc_lang=en\&sid=1

Jackson, R. E., \& Swor, R. A. (1997). Who Gets Bystander Cardiopulmonary Resuscitation in a Witnessed Arrest? Academic Emergency Medicine, 4(6), 540-44. http://dx.doi.org/10.1111/j.1553-2712.1997.tb03574.x

Jacobs, I. G., Finn, J. C., Jelinek, G. A., Oxer, H. F., \& Thompson, P. L. (2011). Effect of Adrenaline on Survival in out-of-Hospital Cardiac Arrest: A Randomised Double-Blind Placebo-Controlled Trial. Resuscitation, 82(9), 1138-43. http://dx.doi.org/10.1016/j.resuscitation.2011.06.029

Jafarian, A. (2002). Survey Successful Cardiopulmonary Resuscitation in the Hospital Shohada 7th Tir (2000). $J$ Iran Univ Med Sci, 3(30), 327-31. Retrieved December 26, 2015, from https://scholar.google.com/ scholar?q=Survey + successful + cardiopulmonary + resuscitation + in + the + hospital + Shohada +7 th + Tir\&btnG $=$ $\& h l=$ en\&as_sdt $=0 \% 2 \mathrm{C} 5 \# 0$

Jafarian, A. A. (2002). Evaluation of Succesful Cardiopulmonary Ressuscitation (CPR) Rate in Haftom Teer Hospital. Razi Journal of Medical Sciences. Retrieved December 26, 2015, from http://rjms.iums.ac.ir/browse.php?a_id=300\&slc_lang=en\&sid=1\&printcase $=1 \&$ hbnr $=1 \&$ hmb $=1$

Jeresaty, R. M., Liss, J. P., \& Basu, S. K. (1973). Long-Term Follow-up of 122 Patients Who Survived Cardiac Arrest. Resuscitation, 2(3), 191-98. http://dx.doi.org/10.1016/0300-9572(73)90044-0

Karetzky, M., Zubair, M., \& Parikh, J. (1995). Cardiopulmonary Resuscitation in Intensive Care Unit and Non--Intensive Care Unit Patients: Immediate and Long-Term Survival. Archives of Internal Medicine, 155(12), 1277-80. http://dx.doi.org/10.1001/archinte.1995.00430120054007

Keim, S. M., Anderson, K., Siegel, E., Spaite, D. W., \& Valenzuela, T. D. (2001). Factors Associated with CPR Certification within an Elderly Community. Resuscitation, 51(3), 269-74. http://dx.doi.org/10.1016/ S0300-9572(01)00418-X

Khalafi, K., Ravakhah, K., \& West, B. C. (2001). Avoiding the Futility of Resuscitation. Resuscitation, 50(2), 161-66. http://dx.doi.org/10.1016/S0300-9572(01)00332-X

Mh, E., La, B., Hc, B., Ha, M., \& Gen. (1998). Survival after in-Hospital Cardiopulmonary Resuscitation. J Gen Intern Med, 13(0), 805-16.

Monsieur, K. G., Regge, M. D., Vansteelandt, K., Smet, J. D., Annaert, E., Lemoyne, S., ... Calle, P. A. (2012). Excessive Chest Compression Rate Is Associated with Insufficient Compression Depth in Prehospital Cardiac Arrest. Resuscitation, 83(11), 1319-23. http://dx.doi.org/10.1016/j.resuscitation.2012.07.015

Moretti, M. A., Cesar, L. A. M., Nusbacher, A., Kern, K. B., Timerman, S., \& Ramires, J. A. F. (2007). Advanced Cardiac Life Support Training Improves Long-Term Survival from in-Hospital Cardiac Arrest. Resuscitation, 72(3), 458-65. http://dx.doi.org/10.1016/j.resuscitation.2006.06.039

Mutchner, L. (2007). The ABCs of CPR--Again. The American Journal of Nursing, 107(1), 60-69\&69-70. http://dx.doi.org/10.1097/00000446-200701000-00024

Nasiripour, A. A., Masoudi, A. I., \& Fathi, E. (2012). The Relationship of CPR Success and Time of Patients' Referring to Emergency Department. Journal Mil Med, 14(1), 21-25. Retrieved December 27, 2015, from http://www.militarymedj.ir/browse.php?a_code=A-10-729-1\&slc_lang=en\&sid=1

Parhizgari, N. (2009). Survey of Cardiopulmonary Resuscitation Therapeutic Process in Shariaati Emergency Ward Hospital. Tehran University of Medical Science.

Roosa, J. R., Vadeboncoeur, T. F., Dommer, P. B., Panchal, A. R., Venuti, M., Smith, G., ... Bobrow, B. J. (2013). CPR Variability during Ground Ambulance Transport of Patients in Cardiac Arrest. Resuscitation, 84(5), 592-95. http://dx.doi.org/10.1016/j.resuscitation.2012.07.042

Saifi, F., Sharafi, F., Astangy, S., \& Esmaeili, K. (2010a). Success Rate of Cardiopulmonary and Brain 
Resuscitation in Centers Kermanshah University of Medical Sciences (2000-2005). J Kermanshah Univ of Med Sci, 3(14), 273. Retrieved December 26, 2015, from https://scholar.google.com/scholar?q= Success + rate + of + cardiopulmonary + and + brain + resuscitation + in + centers + Kermanshah + University + of + Med ical + Sciences $+\% 282000-2005 \% 29 \& b \operatorname{tnG}=\& h \mathrm{hl}=$ en\&as_sdt $=0 \% 2 \mathrm{C} 5 \# 0$

Saifi, F., Sharafi, F., Astangy, S., \& Esmaeili, K. (2010b). Success Rate of Cardiopulmonary and Brain Resuscitation in Centers Kermanshah University of Medical Sciences (2000-2005). J Kermanshah Univ of Med Sci, 3(14), 273. Retrieved December 27, 2015, from https://scholar.google.com/scholar?q=Success + rate + of + cardiopulmonary + and + brain + resuscitation + in + centers + Kermanshah+University + of + Medical + Sci ences\&btnG $=\& \mathrm{hl}=$ en\&as_sdt $=0 \% 2 \mathrm{C} 5 \# 0$

Salari, A., \& Mohammadnejad, E. (2010). Survival Rate and Outcomes of Cardiopulmonary Resuscitation. Iranian Journal of Critical, 3(2), 45-49. Retrieved December 26, 2015, from $\mathrm{http}: / /$ www.inhc.ir/browse.php?a_code=A-10-120-2\&slc_lang=fa\&sid $=1 \& \mathrm{ftxt}=1$

Salari, A., et al. (2010). Survival Rate and Outcomes of Cardiopulmonary Resuscitation. Iranian Journal of Critical Care Nursing, 3(2), 45-49.

Sandroni, C., Nolan, J., Cavallaro, F., \& Antonelli, M. (2007). In-Hospital Cardiac Arrest: Incidence, Prognosis and Possible Measures to Improve Survival. Intensive Care Medicine, 33(2), 237-45. http://dx.doi.org/10. 1007/s00134-006-0326-z

Taffet, G. E., Teasdale, T. A., \& Luchi, R. J. (1988). In-Hospital Cardiopulmonary Resuscitation. JAMA : The Journal of the American Medical Association, 260(14), 2069-72. http://dx.doi.org/10.1001/jama.1988. 03410140081027

Timerman, S., Cardoso, L. F., Ramires, J. A. F., \& Halperin, H. (2004). Improved Hemodynamic Performance with a Novel Chest Compression Device during Treatment of in-Hospital Cardiac Arrest. Resuscitation. http://dx.doi.org/10.1016/j.resuscitation.2004.01.025

Travers, A. H., Rea, T. D., Bobrow, B. J., Edelson, D. P., Berg, R. A., Sayre, M. R., ... Swor, R. A. (2010). Part 4: CPR Overview: 2010 American Heart Association Guidelines for Cardiopulmonary Resuscitation and Emergency Cardiovascular Care. Circulation, 122(SUPPL. 3), 676-85. http://dx.doi.org/10.1161/CIRCULA TIONAHA.110.970913

Vukmir, R. B. (2006). Survival from Prehospital Cardiac Arrest Is Critically Dependent upon Response Time. Resuscitation, 69(2), 229-34. http://dx.doi.org/10.1016/j.resuscitation.2005.08.014

Wlldsmith, J. (1972). Results Of Resuscitation Following Cardiac Arrest A Review From A Major Teaching Hospital. British Journal Of..., 44(7), 716-72. Retrieved December 28, 2015, from http://bja.oxfordjournals.org/content/44/7/716.short

Youn, C. S., Choi, S. P., Yim, H. W., \& Park, K. N. (2009). Out-of-Hospital Cardiac Arrest due to Drowning: An Utstein Style Report of 10 Years of Experience from St. Mary's Hospital. Resuscitation, 80(7), 778-83. http://dx.doi.org/10.1016/j.resuscitation.2009.04.007

\section{Copyrights}

Copyright for this article is retained by the author(s), with first publication rights granted to the journal.

This is an open-access article distributed under the terms and conditions of the Creative Commons Attribution license (http://creativecommons.org/licenses/by/3.0/). 